\title{
Condições de produção discursiva de trabalhadores da economia solidária ${ }^{1}$
}

Darlene Arlete Webler

\begin{abstract}
The analysis of the discourse practices of workers who constitutes and enable cooperatives organizations of auto management belonging to the Solidary Economy in Rio Grande do Sul appears as our main subject in this approach. We investigated industrial production in the auto management model, created from the bankruptcy of capitalist management enterprises. The study deals with the observation of the discourse about the process and practices of auto managing, of auto management supporters and intellectuals which work togheter with the subjects involved in these experiences. In this process ideas and beliefs are "disarranged", "rearranged" and "transformed" in non linear ways. These new social practices and discourses of auto managing organization of workers can be found in different moments of the humanity history, and they leads us to think about the discourse as a resonance of senses. The theoretical-methodological option of this study is based on the Discourse Analysis (AD), of French origin, whose the main characteristic is the focus on the process of production of meaning and their social-historical identities.
\end{abstract}

Keywords: Conditions of production, Subjects, Discourse

Resumo: A análise das práticas discursivas de trabalhadores que constituem e viabilizam organizações cooperativas de autogestão, inscritas na Economia Solidária no RS, figura como tema central na presente abordagem. Investigamos empreendimentos de produção industrial na modalidade da autogestão, instaurados a partir da falência de empresas de gestão capitalista. O estudo passa pela observação do processo de discursivização das práticas de sujeitos autogestionários, de apoiadores da autogestão e de intelectuais orgânicos da classe trabalhadora, em que saberes são "desarranjados", "rearranjados" e "transformados", de forma não-linear. Essas novas práticas sociais e discursivas da organização autogestionária de trabalhadores podem ser encontradas em diferentes momentos da história da humanidade, o que

1 Este artigo foi produzido a partir da nossa tese "As Práticas Discursivas dos Trabalhadores em Empreendimentos de Produção Industrial Autogestionária”, sob a orientação da Prof ${ }^{a}$ Ana Zandwais (PPGL/UFRGS), defendida em 2008. 
nos conduz a pensar sobre as ressonâncias discursivas e redes interdiscursivas. Para tanto, a opção teórico-metodológica do presente estudo está alicerçada na Análise do Discurso (AD), de linha francesa, caracterizando-se pelo enfoque nos processos de produção de sentido e de suas determinações histórico-sociais. Esta teoria nos permite pensar nas condições de produção dos discursos produzidos no domínio da autogestão operária.

Palavras-chave: Condições de Produção; Sujeitos; Discursos

\section{Introdução}

A presente abordagem toma como foco central os discursos produzidos por trabalhadores que se inserem em organizações cooperativas autogestionárias, instauradas a partir de massas falidas, ou seja, de empresas capitalistas que faliram. Trata-se de formas associativas de autogestão operária que têm seu reflorescimento recente no Brasil, mais especificamente no Rio Grande do Sul, visto que seu desenvolvimento se efetiva a partir do início da década de 1990.

Atualmente, as cooperativas de trabalhadores autogestionários se apresentam como alternativas de geração de trabalho e renda, atendendo a diversas demandas de tendências regionais e envolvendo diferentes sujeitos do meio popular. De modo especial, revelam-se instâncias organizativas com novas relações sociais de produção, com novas concepções de trabalho e novas práticas discursivas, tendo em vista que a gestão patronal dá lugar à gestão solidária, democrática e autônoma do conjunto dos trabalhadores, à luz dos princípios da Economia Solidária.

Nosso propósito reside em tecer algumas reflexões acerca dos processos de discursivização dessa forma de organização popular e alternativa, que se mostra adversa às atuais tendências sócio-políticas e econômicas. Considerando que a dinâmica do mercado capitalista mundial está voltado, prioritariamente, para o fortalecimento de grandes corporações lucrativas, promovendo a exclusão de grande parte da humanidade, podemos dizer que a organização autogestionária de trabalhadores na perspectiva da Economia Solidária é, de fato, um modo de resistência a tal processo excludente. Os discursos ali produzidos constituem-se discursos de resistência, atravessados por saberes confluentes, contraditórios e até antagônicos à autogestão.

Esta abordagem revela-se, ao mesmo tempo, fascinante e de grande pertinência aos estudos acadêmicos da linguagem. Trata-se da discursivização deste novo jeito de trabalhadores organizarem-se em uma dinâmica que é adversa a das empresas tradicionais capitalistas, experimentando verdadeiras relações de solidariedade, sobre as quais já formulavam reflexões e implementavam práticas sociais intelectuais orgânicos como Kropotkin, Lênin, Trotsky, Gramsci e outros. Nesse sentido, entendemos que nada mais adequado para atingir tais propósitos do que fazê-lo na perspectiva da Análise do Discurso, visto que as bases epistemológicas da Análise do Discurso, de linha francesa, a partir de Michel Pêcheux, permitem que façamos a incursão de abordagens de ordem sócio-históricopolítica, à luz do materialismo dialético e histórico, situando-as nos estudos da linguagem em uma articulação de teoria e prática.

Ao propormos a análise da Formação Discursiva dos Trabalhadores Autogestionários (FDTA), temos em vista a observação de traços da cultura e da consciência associativa no discurso destes operários e de discursos provindos de outras formações discursivas, bem como das contradições que possivelmente permeiam e se revelam de diferentes formas no 
processo de organização autogestionária. Nessa linha, é importante a observação de saberes que emergem da FDTA, que ora se discursivizam, ora silenciam (ou são silenciados), apagando concepções sócio-históricas provindas de saberes anarquistas, anarco-sindicalistas, socialistas, comunistas, e/ou até de saberes liberais. Tomamos a FDTA como a Formação Discursiva de Referência, que se articula e é permeada por outras formações discursivas, e que, aqui, agrupamos em duas: a Formação Discursiva Empresarial (FDE) e a Formação Discursiva Político-Pedagógica Autogestionária (FDPPA). Naquela, na FDE, se inscrevem saberes próprios das relações empresariais capitalistas, em que figuram patrão e empregado, em uma permanente relação de submissão/dominação entre capital e trabalho; ao passo que os saberes da FDPPA podem ser associados aos saberes e práticas da FDTA, atravessando-a e servindo de apoio para a implementação das práticas autogestinárias. Os saberes da FDE são antagônicos aos saberes da FDPPA e, por isso, precisam ceder lugar para que a autogestão operária efetivamente se instaure. Cabe observar que, dada a peculiaridade de a FDTA ser oriunda de massa falida capitalista, ela é permeada predominantemente por saberes advindos de formações discursivas articuladas às concepções de solidariedade, mútua ajuda e autogestão (FDPPA), mas também de formações discursivas antagônicas que representam saberes e práticas liberais, individualistas e competitivas - da FDE.

Considerando que a gestão coletiva operária tem seu surgimento a partir do fracasso administrativo da gestão empresarial, observamos, à luz dos Estudos da Linguagem, como e em que medida as formas de exploração capitalista são "desarranjadas" e "re-arranjadas" para ter, no cooperativismo autogestionário, uma dinâmica solidária, democrática e autônoma de planejamento, de gerenciamento e de distribuição dos resultados econômicos.

\section{Condições de produção do discurso}

Relativamente às condições de produção do discurso, as formulações de Pêcheux (1969) conduzem para a compreensão de condições de produção de um discurso a partir da instância em que ele ocorre. Em suas palavras, encontramos a seguinte proposta de designação: "o conjunto de mecanismos formais que produzem um discurso de tipo dado em 'circunstâncias' dadas" (Pêcheux, 1969: 74) e "mecanismo de colocação dos protagonistas e do objeto de discurso" (idem, p. 78). Já, em 1975, as formulações de Pêcheux em conjunto com Fuchs tratam inicialmente da noção de condições de produção como estáveis e homogêneas no processo discursivo; no entanto, os autores admitem a possibilidade de haver "certas ambigüidades" - remetendo a determinações que caracterizam um processo discursivo e a características múltiplas de uma "situação concreta" -, e, diante disso, apontam para "a necessidade de reconhecer a defasagem entre o registro do imaginário e o exterior que o determina" (idem, p. 182). Podemos pensar que os autores já estão abrindo uma "brecha" para o princípio da heterogeneidade. Importante observar que, conforme Courtine (1982), entre o período de formulação da Análise Automática do Discurso de 1969 e de 1975 (AAD/69 e AAD/75), Pêcheux é fortemente influenciado pelas teses althusserianas. Nessa perspectiva, é pela existência dos aparelhos ideológicos de Estado que a reprodução das relações sociais é materialmente assegurada.

Em 1981, Courtine postula uma transformação da noção das condições de produção do discurso, subdividindo esta noção em uma dimensão teórica e outra empírica. Teoricamente, a noção vem associada a uma determinada formação discursiva, em uma determinada contingência histórica. Na perspectiva empírica, Courtine repensa as condições de produção do discurso, passando a chamá-las de condições de formação da produção do discurso. Ele reordena esta noção "na análise histórica das contradições 
ideológicas no conceito de formação discursiva" (Idem, p. 22). Assim, as condições de produção do discurso situam-se, por um lado, na contingência histórica e, por outro, na emergência do acontecimento.

Nessa ótica, a FDTA se instaura com o acontecimento da falência efetiva da empresa capitalista, constituindo-se em massa falida, e posterior organização da empresa de autogestão operária; mas também na própria história da organização operária internacional com vistas à sua emancipação e à superação do modo de produção capitalista. Todo o processo de organização dos trabalhadores, de constituição jurídica do empreendimento e de vivência da autogestão é permeado por saberes historicamente construídos pelas classes trabalhadoras e seus intelectuais orgânicos.

Considerando que as determinações históricas estão relacionadas aos processos discursivos na forma de descontinuidade, de ambigüidade, de contradição, e a formação discursiva, cujas fronteiras são instáveis, se caracteriza pela sua condição de contradição (pelas relações de contradição que povoam o seu interior), temos como resultado a heterogeneidade das condições de produção do discurso. Ao falar da contradição como princípio constitutivo de qualquer formação discursiva, Courtine remete a Pêcheux (1975) quanto ao espaço da reprodução / transformação / contradição das relações de produção. Só a diferença não basta para haver contradição, é preciso uma forte relação de contradição - por exemplo, a relação entre a Teologia da Libertação (a mais progressiva corrente da Igreja Católica) e a cúpula conservadora dirigente da Igreja Católica (o grupo ligado ao vaticano). Trata-se de diferenças tão profundas nas relações que se estabelecem entre elas que, muitas vezes, são projetados domínios de saberes completamente divergentes entre si, o que vem a mostrar o acentuado caráter heterogêneo da formação discursiva católica.

Nessa perspectiva, pensemos na constituição do corpus discursivo de análise. Ele é atravessado por relações contraditórias, antagônicas e de aliança, com outros discursos - o que o caracteriza como heterogêneo e não-linear. De acordo com Courtine (1981: 24), o corpus discursivo se apresenta como "um conjunto de seqüências discursivas, estruturado conforme um plano definido em referência a esse estado das condições de produção do discurso". Portanto, para constituir um corpus deve-se seguir um plano de pesquisa. Diante do universal do discurso - totalidade do discurso operário - a operação de coleta do corpus tem seu início pela extração de sequências que delimitam um campo discursivo de referência - nesta pesquisa, é o discurso operário industrial autogestinário, que se situa no entremeio do discurso político e sindical.

\section{Os discursos da e na i autogestão}

Articular a noção de autogestão significa pensar formas de auto governo, maneiras de participação das pessoas nas tomadas de decisões em uma organização social associativa anti-burocrática. A autogestão se faz na ação das pessoas e deve ser construída no dia-a-dia. Ela pode ser institucionalizada, mas o que a faz efetivamente são suas relações práticas. Assim, pensemos em uma linha histórica em que a autogestão e a autonomia não aparecem apenas como um objetivo a ser alcançado, mas representam a própria existência histórica real das lutas operárias.

Considerando a autogestão operária contemporânea, especificamente os empreendimentos de produção industrial, da Grande Porto Alegre e Vale dos Sinos, observamos que estes são formados por uma maioria de operários que vivenciou processos produtivos e relações capitalistas de produção. Muitos destes operários, possivelmente, optaram pela forma cooperativa motivados mais pela manutenção dos postos de trabalho e sua remune- 
ração, do que pela convicção da construção de novas relações sociais de trabalho. Trata-se daquilo que comumente se designa, na autogestão, como a "cultura de firma". Esta precisa necessariamente ser superada para que a identidade autogestionária seja instaurada no empreendimento operário. O processo de formação e organização de algumas das empresas autogestionárias de produção industrial, como é o caso da $\mathrm{CTMC}^{2}$, em Canoas/RS, foi acompanhado diretamente por lideranças sindicais, representantes da $\mathrm{SEDAI}^{3}$ e assessores da $\mathrm{ANTEAG}^{4}$, cujas condições de formação dos saberes estão associadas a concepções de solidariedade e mútua-ajuda, de forma que seja possível dizer que estes saberes encontram contingência histórica em domínios de saberes anarquistas, socialistas e comunistas.

$\mathrm{Na}$ autogestão operária, embora ainda seja possível perceber a reprodução de algumas relações capitalistas, as relações de trabalho e de utilização dos meios de produção são transformadas profundamente. Como os operários autogestionários passam a ser donos dos meios de produção, além da sua força de trabalho, não mais existe a figura do patrão, o que significa que as relações entre os próprios trabalhadores não mais são de submissão a ordens de um patrão ou um administrador, mas implica todos os trabalhadores como uma coletividade participar na tomada das decisões acerca da gestão do empreendimento, bem como respeitá-las, submetendo-se a elas. Concretamente, tal dinâmica de socialização de todo o processo produtivo mostra-se, ao mesmo tempo, fascinante e complexa aos sujeitos da autogestão, visto que a implementação de princípios como da democracia, da transparência, da socialização, da autonomia, representam um grande desafio a todos que vivenciaram profundas relações individualistas. Entre as implicações da prática autogestionária, destacamos a socialização dos conhecimentos e da distribuição dos resultados econômicos no processo autogestionário.

Cabe chamar a atenção para os necessários processos de desarranjo e de re-arranjo de saberes e práticas individualistas e competitivos até sua transformação em saberes e práticas de autogestão. Trata-se de processos não-lineares e não-estáveis sobre os quais passaremos a assentar nossas reflexões e análises.

Esta subseção, que trata dos discursos da e na autogestão, se caracteriza pelo perfil analítico dos saberes e práticas discursivas da formação discursiva que tomamos como referência - a FDTA, bem como das relações que se estabelecem entre ela e os diferentes domínios de saberes que constituem a FDE e a FDPPA. Nosso percurso de análises, caracterizado pela estreita articulação da teoria e da prática, apresenta questões agrupadas da seguinte forma: 2.1. Breve Contextualização do Processo de Formação da CTMC; 2.2. Saberes empresariais que emergem nas práticas discursivas autogestionárias; 2.3. Saberes que rompem com os saberes empresariais; e 2.4. Novos saberes que instauram a Formação Discursiva dos Trabalhadores Autogestionários.

Nesse sentido, analisamos sequências discursivas (Sds), recortadas de materiais impressos e, principalmente, de entrevistas com sujeitos que se inscrevem na FDPPA, bem como analisamos sequências discursivas de referência (Sdrs), recortadas de entrevistas com sujeitos autogestionários. Nas práticas discursivas destes últimos sujeitos, procuramos observar como se dá o processo de desarranjo de saberes empresariais e o re-arranjo destes para que predominem os saberes associativo-autogestionários sobre aqueles, contribuindo para a transformação das relações de dominação/submissão de patrões sobre operários em relações alicerçadas na solidariedade, mútua ajuda, co-gestão e autonomia de novos trabalhadores.

2 CTMC: Cooperativa de Trabalhadores Metalúrgicos de Canoas/RS.

3 SEDAI: Secretaria Estadual de Desenvolvimento e Assuntos Internacionais.

4 ANTEAG: Associação Nacional dos Trabalhadores em Empresas de Autogestão e Participação Acionária. 


\subsection{Breve contextualização do processo de formação da CTMC}

A Cooperativa dos Trabalhadores Metalúrgicos de Canoas (CTMC) é uma das mais importantes experiências autogestionárias, na produção industrial, instaurada a partir de massa falida, em abril de 2001. A história do seu surgimento nos foi contada por sujeitostrabalhadores que foram empregados da antiga Metalúrgica Vogg, que vivenciaram o período pré-falimentar e falimentar da empresa, que participaram do processo de organização dos trabalhadores, sendo protagonistas na instauração da CTMC e continuando nela até hoje na condição de trabalhadores-associados. Também contribuíram no resgate desta história alguns trabalhadores de outras metalúrgicas e integrantes do sindicato dos metalúrgicos de Canoas.

A Metalúrgica Vogg foi uma empresa no ramo da caldeiraria pesada, de porte médio, importante para a economia regional ${ }^{5}$, especialmente na década de 1970 e 1980 . Já na década de 1990, ela passou a apresentar crescentes sinais de declínio, resultado de máadministração, o que culminou com seu fechamento (falência), em abril de 2001. Houve um período, de cerca de seis meses, em que a fábrica ficou fechada e os trabalhadores da Vogg e de outras empresas, por intermédio do sindicato, permaneceram acampados no pátio da metalúrgica para guardar as instalações e máquinas, evitando roubos e destruições patrimoniais. Este período foi marcado por relações de solidariedade entre os trabalhadores, propiciando a organização desses trabalhadores.

De acordo com o trabalhador-associado da CTMC e ex-sócio do sindicato, J.H., a instância sindical teve um papel fundamental em toda a discussão e processo preparatório da cooperativa; assim como, outras entidades/instituições que apostaram na modalidade autogestionária, a saber: Governo do Estado do RS (1999-2002), através SEDAI; a ANTEAG; as Pastorais Sociais (alguns setores progressivos da Igreja Católica); sindicatos apoiadores; partidos políticos de esquerda (especialmente correntes do PT).

Há consenso, entre quem participou do processo de criação da cooperativa, de que sua organização não foi um movimento espontâneo dos trabalhadores metalúrgicos e nem de curto prazo. Por um lado, criaram-se condições de fundação da cooperativa pela situação de falência da empresa capitalista e o consequente fechamento de mais de cem postos de trabalho (100 vagas); por outro, houve condições sócio-político-históricas construídas pelo movimento operário. A soma de diversas forças (instituições) foi fundamental para que a autogestão fosse assumida e implementada pelos trabalhadores, ainda que esse debate não tivesse aceitação de alguns grupos dentro do(s) sindicato(s), do(s) partido(s) e outros. Foram necessários serem travados muitos debates sobre cooperação e suas implicações na vida das pessoas (que tipo e como); e continuam presentes - agora, em outros níveis - nas pautas das discussões e práticas dos sujeitos autogestionários. A organização dos associados da CTMC faz-se tarefa contínua para que a dinâmica da autogestão operária se mantenha dentro dos seus verdadeiros princípios.

A realidade mostra que não basta vontade de fazer um trabalho em e no coletivo; é preciso que os dirigentes tenham ciência da vontade política do grupo e da opção efetiva por mudanças das práticas sociais. A dificuldade de trabalhar em grupo está relacionada ao necessário desarranjo de saberes empresariais, seu rearranjo e sua transformação em novos saberes, que são opostos aos anteriores. A mudança das práticas se constitui em um processo lento e não-linear, sendo fundamental que haja paciência histórica, da qual fala

5 A Vogg foi responsável, por exemplo, pela produção das estruturas e construção da Ponte do Guaíba projetada para permitir, ao mesmo tempo, a ligação rodoviária Porto Alegre-Guaíba e a passagem fluvial de navios de grande porte, permitida por um sistema de levantamento de parte da ponte. 
Lênin, e intelectuais orgânicos, a partir de Gramsci, para orientar e ajudar a emancipar os sujeitos que se colocam o desafio da autogestão.

Desde a criação da CTMC, os meios de produção (pátio industrial, instalações, máquinas) estiveram nas mãos dos cooperados - inicialmente, por locação; e depois, por aquisição. Como proprietários da força de trabalho e dos meios de produção, os associados, desde 2001, exercitam o gerenciamento coletivo do empreendimento metalúrgico (CTMC) e a vivência de relações de solidariedade, ainda que constantemente atravessadas por saberes e práticas herdadas da antiga gestão empresarial. Lembramos que, à luz do materialismo dialético e histórico, a categoria da contradição é inerente a todo processo que visa à transformação.

A CTMC representa uma desafiadora experiência de trabalho coletivo e de gerenciamento dos trabalhadores, que historicamente foram delegados à condição de incapaz para tal. A Economia Solidária, juntamente com a ANTEAG e o Sindicato dos Metalúrgicos de Canoas (STIMMMEC), teve e ainda tem papel importante nesse processo, pois orienta a cooperação não só em relação ao trabalho coletivo, em equipes, mas para a coletivização de todo o processo de gestão - participação de todos no planejamento, na produção, na avaliação e na distribuição dos resultados. Tomemos a fala do trabalhador-associado e integrante do conselho administrativo da CTMC, O.M. ${ }^{6}$, sobre a experiência de autogestão da cooperativa, aqui apresentada como $\mathrm{Sdr} 1$ :

Sdr 1 - Provamos que somos capazes quando, em maio de 2001, assumimos esta empresa com 101 trabalhadores e hoje com 140 sócios com vez e voz, expandindo os negócios, fabricando estruturas metálicas, equipamentos para refinarias, empresas de celulose, caldeiras, contâiners, entre outros. (O.M.)

Nesta Sdr 1, o trabalhador aciona um conjunto de saberes, impregnados na sociedade civil, segundo os quais não cabe aos operários administrarem um negócio, uma empresa industrial, em função de uma suposta incapacidade da classe trabalhadora, historicamente alimentada por classes sociais políticas hegemônicas. Afirmar a capacidade da gestão operária é romper com esses saberes empresariais, é desarranjá-los e rearranjá-los em um lugar totalmente adverso a eles. Em sua fala, na Sdr 1, O.M. ainda enfatiza o desenvolvimento da cooperativa, com a participação ativa dos associados na gestão ("com 140 sócios com vez e voz") e com o aumento dos negócios - reflexo da qualidade dos produtos e conquista de credibilidade no mercado. Essa observação sobre o crescimento dos negócios da cooperativa associada à modalidade autogestionária de operários, tendo em vista que os antigos empresários não conseguiram evitar a falência da empresa, faz repicar sentidos diversos e, especialmente, adversos em relação aos saberes e às práticas capitalistas.

Em suma, a autogestão contraria saberes historicamente defendidos pela classe hegemonicamente econômica. Nesta ótica, pensamos que a autogestão promove a transformação das relações de trabalho, uma vez que ele (o trabalho) passa a ser concebido a partir de outra perspectiva - pela solidariedade, mútua ajuda, democracia, autonomia. Entretanto, a modalidade autogestionária em processo de instauração não está imune a contradições, dados os freqüentes atravessamentos de saberes capitalistas profundamente enraizados nas relações de trabalho de gestão capitalista. Nas próximas seções, as reflexões e análises evidenciam - a partir de Sdrs, recortadas de falas de trabalhadores autogestionários, e de Sds, coletadas de falas de assessores e apoiadores -, o processo de desarranjo e rearranjos de saberes, que promove a transformação e a instauração de uma nova Formação Discursiva: a Formação Discursiva dos Operários Autogestionários.

6 Entrevista ao Jornal Diário de Canoas, em 19/05/2005. 


\subsection{Saberes empresariais que emergem nas práticas discursivas autogestionárias}

Considerando que o objeto de nossa pesquisa são os empreendimentos de produção industrial autogestionária formados a partir de massa falida, os trabalhadores fizeram a experiência de viver relações patronais e, posteriormente, optaram por novas relações - de mútua ajuda, solidariedade e autonomia de gestão, sem patrão e empregado. Entendendo que o imaginário operário está atravessado por saberes empresariais, observamos como se dá tal atravessamento.

Para fins de ilustração, recortamos algumas Sdrs a partir de falas de associados da $\mathrm{CTMC}^{7}$, em resposta às questões "Você foi trabalhador da Vogg (Metalúrgica capitalista) antes da falência? Como foi?" e "Como é trabalhar aqui na cooperativa, na CTMC?". Vamos à primeira das Sdrs:

Sdr 2 - (...) quando a gente está de macacão, igual a todo mundo, ninguém nos vê como um cara que sabe mais ou menos do que os outros não. Pelo contrário, muitas vezes, o companheiro chega e diz: pô, você é o quê? Você é um operário, você não entende de nada (...). (J.P.)

Nesta Sdr 2, podemos observar que aparecem saberes herdados da empresa capitalista como a percepção de uma condição de operários "iguais" entre si (em "igual $a$ todo mundo"), marcada pelo uso do macacão, que simboliza e concretiza um lugar de inferioridade e de limitação na hierarquia da empresa; portanto, é uma igualdade entre trabalhadores subvalorizados e explorados no mundo do trabalho capitalista. Nesta medida, o operário entende não ter conhecimentos - ou seus conhecimentos serem periféricos - e nem capacidade para o que está além do seu trabalho braçal específico no interior da linha de produção. Sua baixa valorização está atrelada, para ele, ao vestuário que porta: se estiver paramentado como operário, não terá credibilidade; mas, se estiver se apresentando com vestimentas próprias do universo empresarial, será visto como alguém que "sabe" e deve ser respeitado por isso, merecer credibilidade.

A perspectiva de o trabalhador falar sobre a empresa no mercado de trabalho, de opinar sobre a produção, de planejar investimentos, de avaliar o processo da prática de gestão ainda parece ser um lugar estranho e distante dele enquanto sujeito-operário que faz parte de uma empresa que já não tem mais patrão. Mais uma vez, a condição de inferioridade pode ser observada, na fala do metalúrgico ainda, pelo uso do ninguém, na passagem "ninguém nos vê como um cara que sabe mais ou menos do que os outros não", representando um ninguém entre o grupo dos que "não sabem" no interior da empresa, especificamente aqueles que trabalham no setor de produção.

Historicamente, o trabalhador é levado a ocupar tal lugar de ser incapaz e ignorante, em favor de outro(s) que sabe $(m)$ e, por isso, legitimamente, pode (m) mais, ou seja, tem mais poder. $\mathrm{Na}$ empresa industrial capitalista, a distância entre quem trabalha na linha de produção (fábrica) e quem trabalha na estrutura administrativa (escritório) está fortemente marcada. O macacão é vestimenta própria dos operários da fábrica e representa uma das marcas desse distanciamento. Nessa perspectiva, na fábrica, estariam os que não têm conhecimento, os que não sabem ou tem o que falar/opinar, os que apenas sabem fazer o trabalho braçal; ao passo que, no escritório, estariam os que sabem, os que têm conhecimentos, os diplomados.

A resposta de autodefinição de J.P. evidencia esse distanciamento entre fábrica e escritório, mas também entre os próprios trabalhadores do mesmo setor (linha de produção), especialmente na passagem: “pô, você é o quê? Você é um operário, você não

7 As entrevistas foram realizadas entre 26/10/2006 e 12/05/2008. 
entende de nada". Tratam-se de indícios da gestão empresarial presente na autogestão, o que conduz a pensar nas razões de certa desconfiança, de alguns trabalhadores, em relação à "igualdade" nas relações de autogestão entre os trabalhadores de diferentes setores ou níveis de produção - serviços na linha de produção. Essa diferença, entretanto, é apenas tangenciada de modo superficial entre quem está de "macacão" e quem não está. Além de certa desconfiança, pode haver até um sentimento de desconforto do trabalhador diante do desafio de ocupar um lugar legitimamente seu, mas que historicamente lhe foi negado: um lugar de co-responsabilidade pelo processo de gestão do empreendimento.

Essa concepção relativa à detenção dos conhecimentos por quem é dono dos meios de produção ou seus administradores tem suas raízes em práticas de dominação/subordinação patronais associadas a longos processos de silenciamentos sofridos pelas massas populares através de diferentes aparelhos ideológicos, como o religioso, o escolar, o político, o militar, etc. Esses processos de silenciamentos constituem a "cultura do silêncio" - silêncio que aprisiona, que escraviza, que impede a emancipação dos oprimidos, das massas. Segundo essa "cultura", inscrita sob os saberes capitalistas, quem "sabe mesmo" e faz silenciar - pelo temor-é o/um Deus onipotente (que sabe tudo e tem o poder de castigar ou recompensar os humanos) através de seus representantes (papa, bispos, padres, pastores, etc.). Concepção que se reproduz, muitas vezes, em outras instâncias, com direções escolares, partidárias, governamentais, sindicais, militares, etc.

Consideremos agora a Sdr 3, recortada da fala de P.R., em resposta à pergunta "Como é trabalhar aqui na cooperativa, na CTMC?". Vejamos:

Sdr 3 - A gente, que é peão, não reclama se tem muito serviço pra fazê... Pior é não ter o que trabalhá... Se o chefe manda, a gente faz... e fica assim meio sem jeito quando é pra dá palpite... a gente não sabe, não estudou... É melhor, claro, sê tratado bem... (P.R.)

Nesta Sdr 3, o metalúrgico se coloca em um lugar de sujeito-empregado que tem um posto de trabalho e cumpre as tarefas determinadas pelo patrão. Trata-se de um sujeito totalmente identificado com os saberes empresarias capitalistas - da FDE. Esta identificação é tão grande que ele fala como se a gestão ainda fosse da responsabilidade de uma pessoa ou pequeno grupo que tem poder de decisão e dominação sobre os demais, de forma que ele, como "peão", deve submeter-se aos mandos de um "chefe" pela necessidade de manutenção do emprego. Mas, que chefe/patrão? Afinal, P.R. está inserido em uma cooperativa autogestionária e não há mais patrão e empregados, mas trabalhadores organizados para decidir e trabalhar coletivamente.

Aqui é pertinente fazermos uma observação: a dinâmica de organização do trabalho, na CTMC, se dá por equipes de trabalho e conselhos, cada qual com um coordenador. A proposta é de funcionamento coletivo em cada uma dessas instâncias, propiciando a participação de todos.

$\mathrm{Na} \mathrm{Sdr} 3$, observamos, por um lado, a concepção de que "se o chefe manda, a gente (operário) faz"; e, por outro, a percepção de relações de trabalho alternativas às capitalistas: "e fica assim meio sem jeito quando é pra dá palpite... a gente não sabe, não estudou... É melhor, claro, sê tratado bem...". Ao trabalhador-associado, é incômodo o lugar de cogestor de um empreendimento. Mais do que não confiar no gerenciamento operário, ele se coloca como indivíduo que não se sente preparado ("a gente não sabe, não estudou") para a participação ("pra dá palpite"). Voltamos, assim, à questão da condição de inferioridade historicamente imputada à classe trabalhadora. Senso comum que é reproduzido, na sociedade civil, através dos diversos mecanismos ideológicos sob o comando de forças hegemônicas liberais. Segundo Gramsci, trata-se de uma hegemonia de Estado - este enquanto soma da sociedade política e sociedade civil - que é revestida de coerção: "velhas ideologias que dominam pela coerção" (Gramsci, 1997: 66). 
Ao fazer a ressalva de que "é melhor, claro, sê tratado bem", na Sdr 3, P.R. reconhece que, ainda que lhe seja incômoda a posição de um sujeito solicitado a dar sugestões, planejar e avaliar, sente-se melhor com as relações de trabalho na autogestão. Entendemos que o ser tratado bem, para ele, está relacionado a uma condição de relações de trabalho adversa à sua concepção de trabalho e trabalhador - concepção esta em sintonia com os saberes e práticas capitalistas de mercado. Trata-se de um pequeno desarranjo de saber, segundo o qual o patrão domina o operário, para rearranjá-lo logo depois - a eliminação da dominação patronal (que) lhe propicia um sentimento de bem-estar.

Para ilustrar indícios de questionamento de saberes empresariais, em que os sujeitosoperários começam a pensar como sujeitos-autogestionários, trazemos a $\mathrm{Sdr} 4$, recortada de outra fala de N.A., agora em resposta à pergunta "Na sua avaliação, o que mudou na relação de trabalho da época da empresa capitalista para a cooperativa?". Vamos a ela:

Sdr 4 - (...) A gente confunde, às vezes, cooperado, sobra, salário... a gente confunde em falá isso daí... a gente ainda tá gatinhando nesse tipo de coisa (autogestão)... (N.A.)

A confusão entre noções, referida por N.A., reflete o processo de crescente identificação com saberes da gestão operária. Aos poucos, no entanto, é possível observar que, pela prática autogestionária, os trabalhadores-associados vão desconstruindo saberes empresariais e reconstruindo-os de outra forma até que a transformação comece a ser instaurada - este movimento de desconstrução e reconstrução caracteriza-se por atravessamentos de saberes herdados das antigas relações de trabalho e profundamente impregnados nas práticas dos operários. Isso é discursivizado pelo trabalhador em "a gente ainda tá gatinhando nesse tipo de coisa" - na referência às novas relações de trabalho autogestionário que devem substituir as relações de submissão-dominação entre empregado-empregador - a cultura de firma. Esta se caracteriza como cultura de não-participação em processos de planejamento e avaliação, própria das empresas capitalistas. Trata-se de uma cultura que precisa ser superada na autogestão, dando lugar para a cultura da participação que tende a caracterizar a FDTA, com novas relações de gestão da produção.

\subsection{Saberes que rompem com os Saberes Empresariais}

Para pensarmos sobre os saberes que rompem com os saberes do domínio empresarial capitalista, reportamo-nos àqueles saberes inscritos sob o domínio que da FDPPA. É na interlocução com os saberes desta Formação Discursiva e no processo de ruptura com as práticas sociais e discursivas empresariais, da FDE, que os trabalhadores são protagonistas de uma nova FD.

Com a finalidade de analisar quais são os saberes, em que medida e como emergem e contribuem para a instauração da FDTA, apresentamos diferentes Sds, recortadas de entrevistas de representantes sindicais, políticos, governamentais e solidários; e algumas sequências Sdrs, recortadas de falas de trabalhadores autogestionárias com história sindical. Também trouxemos recortes discursivos (Sds) de notícias de jornais relativamente à CTMC, de materiais de formação da Economia Solidária, do Sindicato dos Trabalhadores de Canoas (STIMMMEC) e da ANTEAG.

Em relação à Economia Solidária, no Brasil, ela surgiu timidamente na primeira metade da década de 1980 e fortificou-se a partir da segunda metade, como reação de movimentos sociais ao desemprego crescente e massivo - elemento estrutural do capitalismo. Na realidade, a concepção de relações solidárias de economia já vem sendo colocada em prática por trabalhadores, ensaiada por pensadores e sistematizada por estudiosos, há cerca de dois séculos. A história nos traz diversas experiências de organização da classe trabalhadora sob formas solidárias. Mas, no período mais recente, no Brasil, que surgem, à 
luz da Economia Solidária, as cooperativas de autogestão industrial oriundas de empresas capitalistas que entram em falência - objeto de nosso estudo.

O modo solidário que caracteriza a Economia Solidária reflete o princípio da socialização entre posse e uso dos meios de produção e de distribuição pelos trabalhadores. De acordo com Paul Singer (2000: 13), a Economia Solidária constitui um "modo de produção e distribuição alternativo ao capitalismo, criado e recriado periodicamente pelos que se encontram (ou temem ficar) marginalizados do mercado de trabalho". Podemos dizer que se trata de uma opção, ao mesmo tempo, econômica e político-ideológica.

Cabe registrar que a noção Economia Solidária também é nomeada como Economia Popular Solidária, no RS, e como Socioeconomia Solidária, pelo PACS ${ }^{8}$. Entendemo-la como uma espécie de guarda-chuva, sob o qual estão instituições cujos saberes dialogam entre si e se inscrevem no domínio da FDPPA. Assim, a Economia Solidária pode ser compreendida como uma concepção que se manifesta na atividade sócio-econômica de homens e mulheres que se propõem a agirem coletivamente e a se conscientizarem de seus lugares sociais. Pode ser pensada, ainda, como formação ideológica, que orienta os domínios de saberes com ela identificados. Isso nos conduz a pensar nas relações de identificação do sujeito-enunciador (dos operários autogestionários) com o Sujeito Universal (a Economia Solidária como instância ideológica), através das instituições (sindicais, políticas, associativas, etc.) que cooperam entre si no interior da FDPPA. Neste sentido, podemos dizer que a FDPPA representa a materialidade das práticas sociais e das práticas discursivas autogestionárias à luz da Economia Solidária. Considerando as relações solidárias na CTMC, observamos que elas se inscrevem sob os saberes da Economia Solidária, cujas ressonâncias podem ser encontradas ao longo da história.

Entre outras manifestações discursivas em relação ao apoio da instância sindical na organização da CTMC, destacamos a Sdr 5 (J.H.) e Sd 6 (F.S.), recortadas de respostas às perguntas "Fale um pouco de sua história de sindicalista e, enquanto tal, sobre o processo de organização da CTMC" e "De que forma o sindicato teve participação no processo de organização dos trabalhadores e na constituição da CTMC?”, respectivamente. As sequências são as seguintes:

Sdr 5: (...) o sindicato teve um papel fundamental em toda a discussão, em toda a preparação da cooperativa (...) Pra criar a CTMC, teve vários atores nesse movimento: desde o governo Olívio (RS: 1999-2002), a Sedai, a Economia Solidária, sindicato, igrejas... tudo. Não foi uma coisa minha ou de alguns colegas, mas de muitos companheiros... mais de fora da Vogg do que de dentro, mais de fora da CTMC do que de dentro... (J.H.)

Sd 6 - A Vogg não tinha mais crédito em lugar nenhum... e aí foi, foi, foi... até que eles (proprietários) abandonaram a empresa... fizemos (trabalhadores) uma greve por atraso de pagamento, quatro meses de atraso, e eles abandonaram a empresa... aí tava começando, com a história do Governo Olívio, a discussão da Economia Solidária, de cooperativas de autogestão, de tocar os empreendimentos com os trabalhadores, naquela ótica de que também o trabalhador poderia administrar o negócio... (F.S.)

$\mathrm{Na} \mathrm{Sdr} 5$, há a ênfase à participação do sindicato no processo de organização da CTMC. Isso conduz a pensar no significado dessa opção sindical que se caracteriza como uma opção político-ideológica uma vez que remete à histórica reivindicação de defesa dos interesses proletários associada ao processo de emancipação sócio-econômica dos trabalhadores. E tal opção não é só do sindicato mas também de outras instâncias. Trata-se

8PACS: Instituto de Políticas Alternativas para o Cone Sul 
de iniciativas de cunho sócio-político-ideológico, orientadas de acordo com a concepção da indispensável junção das forças orgânicas das classes proletárias para as importantes conquistas rumo à libertação das massas populares.

$\mathrm{Na} \mathrm{Sd}$ 6, F.S. faz referência ao descrédito da empresa associada ao não-pagamento dos salários e à greve realizada pelos trabalhadores, levando-nos a pensar em crise do capital e, por consequência, nas demissões e forte repressão à organização dos trabalhadores. No entanto, a empresa foi abandonada pelos seus donos. Entendemos que tal prática, por um lado, não faz parte dos saberes empresariais capitalistas, segundo os quais o empregador deveria repreender os trabalhadores em greve, fazendo valer seu poder de dominação na medida em que os culparia pela crise da empresa; e, por outro, revela a histórica face de seu descompromisso com os operários.

F.S. lembra que, nesse período, aflorava a discussão em torno da Economia Solidária, que é assumida por diferentes interlocutores sociais identificados com os saberes da classe trabalhadora e se concretiza em importantes parcerias entre o Governo Popular (1999-2002) e Organizações Não-Governamentais (ONGs) de apoio à autogestão operária, como a ANTEAG e a UNISOL ${ }^{9}$. F.S. destaca que a gestão do empreendimento ser assumida pelos próprios trabalhadores, o que está na contramão dos saberes empresarias. Ela rompe com saberes e práticas capitalistas, desarranjando-os e rearranjando-os, instaurando saberes da autogestão.

A introdução do Programa de Economia Popular Solidária pôs em pauta políticas públicas de fomento à autogestão, especialmente na produção industrial urbana, sendo fundamental, para isso, o convênio firmado entre Governo do Estado (1999-2002), através da SEDAI/RS, e a ANTEAG. Nesse sentido, destacamos a $\mathrm{Sd} 7$ e a $\mathrm{Sd} 8$, recortadas da fala de P.G., em resposta à pergunta "Considerando sua experiência como gestor público, durante o Governo do Estado na gestão de Olívio Dutra (1999-2002) e durante o Governo Municipal de Alvorada (2002-2003), que estabeleceu diálogos com diversos segmentos sindicais e políticos e com governos populares do ABC paulista sobre a Economia Popular Solidária, fale sobre as iniciativas do Governo Olívio Dutra para fomento de cooperativas autogestionárias".

Sd 7 - (...) implantamos, de forma descentralizada, os Centros Regionais de Desenvolvimento, Trabalho e Renda e o Programa de Apoio à Economia Popular Solidária, orientados a partir de uma leitura da realidade e da perspectiva estratégica de desenvolvimento das principais cadeias produtivas regionais. (...)Para desenvolver o programa (Economia Popular Solidária), o governo precisou buscar o acúmulo pedagógico junto a entidades e organizações da sociedade civil de assessoria e formação ao movimento de economia solidária. Neste sentido, realizou convênio com a ANTEAG para formação estrutural e fluxo organizativo do Programa. Num segundo momento, foram estabelecidos convênios com uma rede de apoio formada por ONGs e universidades na implementação do plano operacional. (P.G.)

Sd 8 - (...) é inegável a importância que teve o apoio do Governo do Estado e do Governo Federal na viabilização de empreendimentos como a CTMC. Cerca de 80\% dos seus negócios recentes são gerados direta ou indiretamente pela estrutura e política governamental. Exemplo concreto é o PAC ${ }^{10}$ que financia a construção do parque naval no RS, para o qual a CTMC é a principal construtora de navio. (P.G.)

A compreensão de que é papel do Estado o fomento às potencialidades regionais,

9 UNISOL: União e Solidariedade das Cooperativas e Empreendimentos de Economia Solidária do Brasil. 10 PAC é o Programa de Aceleração do Crescimento, implementado pelo Governo Federal, em início de 2008. 
respeitando as características históricas e culturais da matriz produtiva em cada região do Estado, apoiando às micro, pequenas e médias empresas já existentes e incentivando a instauração de outras iniciativas populares, resulta em iniciativas concretas, citadas na $\mathrm{Sd}$ 7, como os Centros Regionais de Desenvolvimento, Trabalho e Renda e o Programa de Apoio à Economia Popular Solidário. Trata-se de programas orientados para o desenvolvimento de cadeias produtivas regionais, com a geração de trabalho e renda e qualificação das relações sociais de produção. Cabe salientar que também P.G., evidencia a importância do diálogo e da soma de diferentes forças orgânicas comprometidas com os interesses das massas populares.

Na Sd 8, encontramos a ponderação acerca da importância dos recursos econômicos destinados aos empreendimentos de autogestão operária como forma de assegurar sua sobrevivência e viabilidade no mercado capitalista. Esta ponderação remete, por um lado, à polêmica e, por vezes, incômoda discussão sobre a viabilização de empreendimentos autogestionários sem apoio econômico governamental; e, por outro, à fundamental condição de independência do empreendimento em relação ao recebimento de recursos públicos para sua viabilização. Podemos pensar ainda nas formas como são injetados tais recursos - de forma direta e, muitas vezes, indireta.

Quanto à passagem de que "cerca de 80\% dos seus negócios recentes são gerados direta ou indiretamente pela estrutura e política governamental" ( $\mathrm{Sd} 8$ ), ressaltamos que, assim como os incentivos públicos, muitas vezes, definem a instauração e viabilização de determinado empreendimento cooperativado, é fundamental que este, aos poucos, criem mecanismos de sobrevivência e auto-sustentação econômica sem depender mais de recursos públicos.

Consideremos agora a perspectiva da ANTEAG, na Sd 9, recortada da fala de E.P., em referência à questão " $O$ cooperativismo autogestionário caracteriza-se pela cooperação e construção coletiva, e o estabelecimento democrático e transparente de critérios da distribuição dos resultados econômicos (planejamento dos serviços; avaliações, distribuição dos resultados; estratégias de investimentos; desenvolvimento da empresa). Como se dá na prática a articulação destes elementos?". A sequência discursiva é a seguinte:

Sd 9 - (...) outro aspecto é a própria formação técnica dos trabalhadores nas suas áreas específicas do trabalho da organização - do trabalho interno - com outra filosofia de trabalho que é a participação democrática e solidária nas decisões coletivas. (...) Aí, termos do trabalhador a iniciativa de não apenas se submeter à ordem, ter a iniciativa de opinar, de decidir, ter a preocupação, ter esse carinho com a empresa, ter essa coisa de buscar ver de outra forma o trabalho. Então, essa cultura do trabalhador tem que ser trabalhada, moldada. (E.P.)

Nos domínios dos saberes da autogestão, o incentivo à formação técnica-profissional dos trabalhadores vem associado à concepção de que é fundamental que os sujeitos da autogestão se qualifiquem profissionalmente e imprimam uma nova postura no exercício das práticas solidárias e democráticas. Nesse sentido, o perfil de trabalhadores submissos, dependentes e silenciados, muda para sujeitos trabalhadores autogestionários com "iniciativa de não apenas se submeter à ordem", mas com a "iniciativa de opinar, de decidir", "de buscar ver de outra forma o trabalho". Cabe ressaltar que o processo de autogestão que promove a participação igualitária na tomada das decisões de todos os trabalhadoresassociados, ainda que com funções diferentes, é um processo lento, não-linear e constantemente atravessado por saberes e práticas contraditórios.

E.P. salienta algumas práticas que devem caracterizam o processo de desconstrução e reconstrução de posicionamentos (saberes e práticas) dos trabalhadores oriundos da gestão 
empresarial centralizada e instauradores da gestão coletiva operária. Podemos mobilizar a idéia de o trabalhador sentir-se à vontade e desejar participar no cotidiano da empresa, tomando-a como realmente sua, em uma relação de co-responsabilidade pelo processo produtivo, como um dos primeiros passos para a incorporação do conceito de autogestão pelo trabalhador - especialmente, no caso da cooperativa ser organizada a partir da massa falida. A afirmação "ter esse carinho com a empresa, ter essa coisa de buscar ver de outra forma o trabalho" faz emergir o sentimento de bem-estar no local de trabalho, já que não se trata mais de um espaço de empregado que vai trabalhar para enriquecer um patrão, mas de um lugar que é seu, que o engrandece e o torna (mais) feliz, da mesma forma que aos outros. Cabe salientar que a transformação da concepção de trabalho e suas relações - na fala de E.P.: "essa cultura do trabalhador tem que ser trabalhada, moldada" (Sd 9) - se constitui um processo complexo, tendo em vista que os saberes relativos à exploração do trabalho são reproduzidos historicamente à classe trabalhadora através dos muitos aparelhos ideológicos presentes em toda a sociedade.

\subsection{Novos saberes que instauram a FDTA}

Considerando que a organização dos trabalhadores, à luz dos princípios da modalidade autogestionária, implica prioritariamente práticas de solidariedade e de participação nos diferentes momentos de tomadas de decisões, articulamos, inicialmente, os depoimentos de N.A. e J.H, que constituem suas respostas à questão "Na sua avaliação, o que mudou na relação de trabalho da época da empresa capitalista para a cooperativa?", e recortamos a $\operatorname{Sdr} 10$ e a Sdr 11:

Sdr 10 - Eu já tava aposentado quando a Vogg acabou. Eu vi ela só decaindo, ficando cada vez pior... Aí, nós criamo a CTMC. No início, foi muito difícil, mas nós se agarremo e lutamo muito. (...) o melhor de tudo é que a gente não ta trabalhando pros outros, ta trabalhando pra nós, em uma empresa que é nossa. (N.A.)

Sdr 11 - Luto para que a gente consiga mostrar para os trabalhadores que não existe dois povo numa empresa, existe um só. Na empresa tradicional, no capitalismo, existe dois "povo": um do escritório e outro da produção e que não querem (patrões) que se mistura. Se misturar, dá problema na divisão do lucro. Então, pra nós é diferente. Todos têm que tá junto, todos têm que saber de todos os problemas da empresa... o que perdeu, o que deixou de ganhar, o que deixou de fazer e assim por diante. (J.H.)

A partir destas Sdrs, podemos pensar no quanto são significativos os processos de organização dos trabalhadores e a mudança que se opera nas relações de trabalho de uma gestão empresarial capitalista para uma autogestão de trabalhadores. Além disso, é importante considerar o nível de dificuldade que representam as necessárias rupturas culturais, profundamente impregnadas na sociedade em que as leis de mercado se sobrepõem a qualquer ordem social.

N.A., na Sdr 10, faz referência às dificuldades enfrentadas pelos trabalhadores no período inicial da instauração da cooperativa e enfatiza a persistência do grupo, a luta conjunta na organização da empresa de operários. E, logo após, N.A. aciona um saber autogestionário segundo o qual o trabalho traz, como resultado, sobras aos trabalhadores, fruto do trabalho coletivo. Notemos que N.A. já se encontrava na condição de trabalhador aposentado quando a empresa capitalista entrou em falência, mas nem por isso deixou de se somar aos demais operários para participar do árduo processo de organização da cooperativa, na qual trabalha ainda hoje e da qual fala com tanto orgulho.

$\mathrm{Na} \mathrm{Sdr} 11$, há um saber autogestionário na passagem "Luto para que a gente consiga mostrar para os trabalhadores que não existe dois "povo" numa empresa, existe um só", 
refletindo o desarranjo e rearranjo de um saber capitalista - de separação entre setores, entre quem manda e quem faz. Ao enfatizar que luta para mostrar aos trabalhadores-associados que, na cooperativa, não existe essa separação entre os que fazem o trabalho braçal e os que fazem o trabalho administrativo (intelectual), J. H. tem a percepção de co-responsabilidade pelo processo de implementação das novas relações de trabalho.

A mistura, mencionada na Sdr 11 remete à interação dos sujeitos entre si e à interlocução nos momentos de tomadas de decisões sobre a cooperativa, desde o planejamento da produção até a distribuição dos resultados econômicos - as sobras conquistadas ao longo do processo produtivo devem ser apropriadas por todos, de acordo com os critérios democraticamente decididos por todos. Trata-se de uma mistura salutar e necessária à dinâmica de autogestão operária enquanto exercício de participação nas diferentes instâncias de discussão e mecanismo para assegurar a solidariedade e democracia nas relações de trabalho. A enunciação de que essa mistura dá problema na gestão empresarial e que se constitui uma prática adversa a da autogestão mostra-se um saber desconstruído e reconstruído segundo os saberes e práticas autogestionárias. O estar junto e o conhecer o funcionamento da cooperativa em todos os aspectos (ganhos, perdas, planos, avaliações, etc.) significa os trabalhadores-associados sentirem-se efetivamente parte do processo e estimularem-se mutuamente para a participação ativa - é o coletivo sobrepondo o individual, sem desrespeitar as individualidades. Além disso, estamos diante do desarranjo do saber historicamente construído, no imaginário da classe trabalhadora, de que os trabalhadores não sabem e nem têm interesse em administrar um empreendimento, necessitando, por isso, dos empregadores para fazê-lo. O rearranjo deste saber está nos discursos e nas práticas da autogestão operária, inscritos nos domínios da FDTA à luz de formações ideológicas de emancipação do proletário.

Para pensar sobre a subjetividade dos sujeitos autogestionários, recortamos as seguintes sequências discursivas da fala de J.H., em diferentes momentos da entrevista, em que o trabalhador autogestionário responde às questões "Há um programa de formação (de educação cooperativa) e/ou qualificação dos trabalhadores nesta cooperativa? Como funciona? Você acha necessário? Você participa?" e "Fale um pouco das perspectivas da CTMC a curto, médio e longo prazos".

Sdr 12 - É muito difícil você deixar de ser um "ex-funcionário": você trabalhou 30 anos soldando, pintando, fazendo a mesma coisa e aí, de repente, alguém diz que você é o dono. Essa disputa de mentalidade... é muito difícil. (J.H.)

Sdr 13 - O trabalhador é mais que um soldador. Não basta ser só soldador, que é o papel do soldador. Mas quando ele levanta a máscara, ele já é um outro agente no processo. Ele é um todo. (...) ele faz o processo. Nós só vamos conseguir mais a partir do momento que o trabalhador sacá isso... porque é mais fácil ele pensar na produção do que agir na produção. (J.H.)

$\mathrm{Na}$ Sdr 12, J.H. articula uma questão relacionada à subjetividade dos sujeitos autogestionários, em especial, daqueles que se inserem em empreendimentos instaurados a partir de massa falida capitalista: "É muito difícil você deixar de ser um "ex-funcionário"”. Cabe lembrar que a concepção de funcionário (e também de ex-funcionário) pertence aos saberes da Formação Discursiva Empresarial (FDE). Dessa forma, na antiga Metalúrgica Vogg (empresa capitalista falida), os trabalhadores foram funcionários, tornando-se exfuncionários quando a empresa entrou em falência e deixou de existir enquanto empresa. Ao organizar o empreendimento autogestionário, a CTMC, os trabalhadores optaram e implementaram novas relações de trabalho caracterizadas pela solidariedade, mútua ajuda e participação de todos os associados em todo o processo produtivo. Isso significa que foi 
(e, na verdade, continua sendo) necessária uma desarticulação de práticas sociais e políticas, ou seja, um processo de desconstrução-reconstrução de saberes empresariais que são transformados em novos saberes e práticas autogestionárias.

Entendemos que J.H., ao afirmar que é difícil deixar de ser ex-funcionário, esteja se referindo a essa desconstrução-reconstrução de saberes para que os trabalhadores autogestionários não pensem como ex-funcionários da Vogg, mas como sujeitos gestores de um empreendimento coletivo que tem uma função social adversa à da empresa capitalista. Notemos que o trabalhador-associado, no fragmento "você trabalhou trinta (30) anos soldando, pintando, fazendo a mesma coisa e aí, de repente, alguém diz que você é o dono. Essa disputa de mentalidade... é muito difícil" (Sdr 16), manifesta sua preocupação em relação à necessária transformação de mentalidade, de cultura. Podemos pensar que, se não for feito o devido desarranjo e rearranjo de saberes de acordo com os princípios da autogestão, há um risco de que trabalhadores cooperativados (antes empregados explorados por patrões) possam reproduzir, em diferentes proporções e características, relações de dominação de uns sobre os outros.

$\mathrm{Na} \mathrm{Sdr}$ 13, o trabalhador fala da característica do ser autogestionário que é mais do que um profissional que transforma a matéria-prima em um produto. Consideramos muito pertinente a associação ilustrativa que J.H. traz do soldador que, ao levantar a máscara que protege seu rosto das faíscas da soldagem, já não é mais só um profissional técnico - ou seja, um soldador -, ele é um agente do processo cooperativo autogestionário, é um sujeito inserido em relações solidárias e co-responsável por elas, é um trabalhador que junto com outros faz acontecer a autogestão operária, em meio a selvageria capitalista: "O trabalhador é mais que um soldador.(...) Mas quando ele levanta a máscara, ele já é um outro agente no processo. Ele é um todo. (...) ele faz o processo". É, na verdade, uma concepção que se inscreve nos domínios de saberes da FDTA.

Podemos apreender, no entanto, a partir do fragmento "Nós só vamos conseguir mais a partir do momento que o trabalhador sacá isso... porque é mais fácil ele pensar na produção do que agir na produção", da Sdr 13, que, muitas vezes, os trabalhadores não têm incorporado essa lógica, esse perfil de sujeito que faz a autogestão. Entendemos que a compreensão de ser sujeito da autogestão - que significa ser mais do que um profissional e gestor de um empreendimento - é fundamental para assegurar o próprio processo autogestionário. Caso contrário - se esse saber não for incorporado pela maioria dos trabalhadores-associados -, pode ali estar uma brecha para que saberes empresariais tomem o lugar dos autogestionários.

\section{Considerações Finais}

No empreendimento autogestionário, ainda que o processo de desarranjo e rearranjo de saberes - da gestão empresarial capitalista para a autogestão - se caracterize como um processo não-linear, que não está imune a contradições, a vivência das relações solidárias de trabalho revela que predominam os saberes e práticas sociais da autogestão operária em relação aos saberes da gestão tradicional capitalista. Grosso modo, é a transformação se sobrepondo à reprodução.

$\mathrm{Na}$ abordagem sobre as condições de produção discursiva e sobre a interpelação ideológica dos sujeitos, acionamos ainda as concepções de esquecimento 1 - lugar da conversão do indivíduo em sujeito - e de esquecimento 2 - lugar da ilusão de autoria -, o que nos permitiu refletir sobre os posicionamentos, as escolhas, os atos dos sujeitos nas práticas sociais e discursivas da autogestão. Muitos dos discursos coletados em entrevistas 
com operários autogestionários, que constituem nosso corpus de análise, encontram ressonância histórica, tratando-se, portanto, de escolhas e discursos com existência anterior às práticas discursivas destes operários, ainda que eles (sujeitos-enunciadores) tenham a ilusão de autoria destas escolhas e discursos, a ilusão de que é "dono" de seu dizer.

As análises das práticas discursivas dos sujeitos autogestionários permitiram pensar que, por exemplo, a participação coletiva nas instâncias de decisão, sobre o processo produtivo, passou a ser algo importante para o trabalhador quando ele começa a desconstruir a concepção de que é cabível a não-participação dos operários, dos empregados, e reconstruí-la para um saber segundo o qual cabe a tomada das decisões (ter voz) aos que promovem a transformação da matéria-prima em mercadoria, que, na verdade, são os que geram sobras que, por sua vez, são apropriadas indevidamente pelos empregadores.

A observação do processo de superação destas práticas deve vir associada à concepção de não-linearidade e não-estabilidade que caracteriza a desconstrução e a reconstrução de saberes e práticas, processo constitutivamente contraditório - conforme já ponderamos reiteradas vezes. É fundamental, nas discussões acerca da autogestão operária, considerar o fato de que o empreendimento autogestionário não é uma "ilha", visto que se insere na dinâmica mercadológica. As relações solidárias de trabalho caracterizam as práticas sociais e discursivas para dentro do empreendimento - ou seja, nas relações estabelecidas entre seus associados -, estendendo-se a instâncias que dialogam com os saberes autogestionários. Estes empreendimentos de autogestão operária precisam também estabelecer relações de mercado - que implicam posturas/práticas competitivas - para fora dele, por uma questão de sobrevivência econômica. Nesse sentido, um dos grandes desafios colocados para os sujeitos autogestionários é instigar constantemente as discussões acerca dos princípios da autogestão para que sejam mantidas as relações de solidariedade, de democracia e de autonomia nas suas práticas sociais.

Simultaneamente ao estabelecimento de relações solidárias com outras experiências de autogestão, o empreendimento autogestionário, muitas vezes, opta pelo seu ingresso na dinâmica produtiva mercadológica, com vistas à obtenção de dividendos econômicos para a empresa de autogestão. Dessa forma, o empreendimento autogestionário operário se comporta, no mercado, como se fosse uma empresa capitalista. A questão que se coloca é se tal prática se trata de uma adaptação a novas formas de o capital se apresentar e, por conseqüência, a possibilidade de os sujeitos autogestionários reverem suas concepções e deixarem sucumbir os princípios da autogestão como norteadores de suas relações solidárias de trabalho. Ponderamos que se trata de uma questão que está colocada permanentemente em pauta nas discussões realizadas por instâncias promotoras e instigadoras da autogestão.

Diante disso, retomamos a questão segundo a qual determinadas "fraturas" no modo de produção das relações de produção propiciam "esfacelamentos" nos modelos de produção capitalista, abrindo "brechas" nas quais o proletariado pode se instalar, como é o caso da organização operária autogestionária. De modo semelhante à existência das contradições ("brechas") da Formação Discursiva Empresarial (FDE) que permitiu o surgimento da Formação Discursiva dos Trabalhadores Autogestionários (FDTA), cujos saberes são antagônicos entre si, as contradições ("brechas") da organização autogestionária podem propiciar o retorno a saberes que são próprios da gestão empresarial. Cabe, aos sujeitos da e na autogestão, a retomada e o debate contínuo acerca dos princípios autogestionários, negando/evitando com veemência a cultura de firma em favor do cultivo da cultura da participação e da ajuda mútua. Vale lembrar ainda que a autogestão operária, enquanto espaço da transformação, se faz no próprio processo de produção e reprodução de saberes e práticas solidárias, ao mesmo tempo em que saberes e práticas capitalistas são desarranjados e rearranjados. 


\section{Referências}

ALTHUSSER, Louis. Aparelhos Ideológicos de Estado. $9^{\mathrm{a}}$ ed., Rio de janeiro, Edições Graal Ltda, 2003.

. Sobre a Reprodução. Petrópolis/RJ, Editora Vozes, 1999.

AUTHIER-REVUZ, J. Heterogeneidade Enunciativa. In: GERALDI, J.V. Cadernos de Estudos Lingüísticos - 9. Campinas: Unicamp / IEL, jul-dez, p. 25-41, 1990.

COURTINE, J.-J. Quelques problèmes et méthodologiques en analyse du discours; à propôs du discours communiste adressè aux chrétiens. In: Langages - n ${ }^{\circ} 62$ (9-127). Paris, juin 1981.

COURTINE, Jean-Jacques; MARANDIN, Jean-Marie. Quel objet pour l'analyse du discours? In: Materialités discursives. (24, 25 e 26 avril, 1980). Nanterre, Presses Universitaires de Lille, 1981.

GADET, Fraçoise; HAK, Toni (orgs). Por uma Análise Automática do Discurso: uma introdução à obra de Michel Pêcheux.. $3^{\text {a }}$ ed., Campinas/SP: UNICAMP, 1997. Tradução Bethania S. Mariani et al.

GADET, Françoise; PÊCHEUX, Michel. A língua Inatingível: o discurso na história da lingüística. Tradução de Bethânia Mariani e Maria Elizabeth Chaves de Mello. Campinas/ SP, Pontes, 2004.

GRAMSCI, A. Os intelectuais e a organização da cultura. $3^{\mathrm{a}}$ ed., RJ: Ed. Civilização Brasileira, 1979.

GRAMSCI, Antonio; BORDIGA, Amadeo. Conselhos de fábrica. São Paulo, Brasiliense, 1981.

GRUPPI, Luciano. O Conceito de hegemonia em Gramsci. Rio de Janeiro, Edições Graal, 1978.

INDURSKY, F.; LEADRO FERREIRA, M.C. Os múltiplos territórios da análise do discurso. Coleção Ensaios, n 12. Porto Alegre, Editora Sagra Luzzatto, 1999.

KROPOTKIN, Piotr A. A ajuda mútua na sociedade moderna. In: TRATEMBERG, M. (Org.). Kropotkin: textos escolhidos. Porto Alegre, Editora L\&PM, 1987.

LÊNIN, Vladimir. Obras escolhidas. Tomo 1. Editora Alfa-Omega. São Paulo, 1982.

Obras escolhidas. Tomo 2.. São Paulo, Editora Alfa-Omega ,1980(a).

Obras escolhidas. Tomo 3. São Paulo, Editora Alfa-Omega 1980(b).

MANCE, E.A. Redes de colaboração solidária: aspectos econômico-filosóficos. Petrópolis, Vozes, 2002.

MARX, Karl. Salário, preço e lucro. Coleção Bases/28. $5^{\text {a }}$ edição, São Paulo, Global Editora, 1987.

MARX, Karl; ENGELS, Friedrich. Obras escolhidas - Volumes I, II e III. SP, Ed. Editora Alfa-Omega, s/d.

ORLANDI, Eni P. A Linguagem e seu funcionamento: as formas do discurso. Campinas, Ed. Pontes, 2003.

Análise do discurso: princípios e procedimentos. $5^{\mathrm{a}}$ edição, Campinas/SP: Pontes, 2003.

PÊCHEUX, Michel. O Discurso: estrutura ou acontecimento. $3^{\text {a }}$ edição, Campinas/SP, Pontes, 2002. 1997(b) .

Semântica e discurso: uma crítica à afirmação do óbvio. Campinas, UNICAMP,

PÊCHEUX, M.; FUCHS, C. A propósito da Análise Automática do Discurso: Atualização e perspectivas (1975). In.: GADET, F.; HAK, T. (orgs.). Por uma análise automática do discurso: uma introdução à obra de Michel Pêcheux. $3^{\text {a }}$ edição, Campinas/SP, Ed. UNICAMP, 1997. 
PINHEIRO, P.S.; HALL, M. A classe operária no Brasil: 1889-1930 (Vol. I). SP, AlfaOmega, 1979.

. A classe operária no Brasil: 1889-1930 (Vol. II). São Paulo, Brasiliense, 1981.

PORTELLI, Hugues. Gramsci e o bloco histórico. Rio de Janeiro: Ed. Paz e Terra, 1977.

SADER, Emir (Org.). Gramsci - poder, política e partido. São Paulo: Expressão Popular, 2005.

. Vingança da História. São Paulo: Boitempo, 2003.

SINGER, P.; SOUZA, A.R. (Orgs). A economia solidária no Brasil: a autogestão como resposta ao desemprego. Coleção Economia. São Paulo: Contexto, 2000.

. Uma utopia militante: repensando o socialismo. Petrópolis: Vozes, 1998.

SOUZA, H. Gestando uma nova cultura: ANTEAG. Revista da autogestão. SP: ANTEAG, 1997.

TAUILLE, J.R. Para (re)construir o Brasil contemporâneo: trabalho, tecnologia e acumulação. RJ: Contraponto, 2001.

TROTSKY, Lev. Textos de Leon Trotski. Coleção Grandes Cientistas Sociais - 22. SP: Ática, 1981.

ZANDWAIS, Ana. Dispositivo de luta política da classe operária brasileira na Primeira Rebública: processo de interpelação do sujeito operário através da imprensa paralela. In: Questões de escrita. P.Fundo, Ed. UPF, 2005, p. 12-29. 